\title{
VASCULAR ABNORMALITIES IN DISCIFORM DEGENERATION OF THE MACULA LUTEA*† DEMONSTRATED WITH FLUORESCEIN
}

BY

\author{
L. LEMKE AND A. JƯTTE
}

From the Department of Ophthalmology, Faculty of Medicine, University of Jena, East Germany

SINCE the description of Junius and Kuhnt (1926), disciform degeneration of the macula lutea has been well-established as a clinical entity. In some cases the earliest change is an oedematous area which soon becomes opaque and is then followed by formation of the typical tumour-like lesion of disciform degeneration. Sharplydefined yellow-white spots frequently surround the central mass. Some authors assume the disease to be a heredodegenerative affection of Bruch's membrane (Brown, 1940). Others regard it as a circulatory disturbance, the result of arteriosclerosis of the choroidal vessels (Thiel, 1963).

The purpose of this paper is to describe certain vascular abnormalities in a case of macular disciform degeneration.

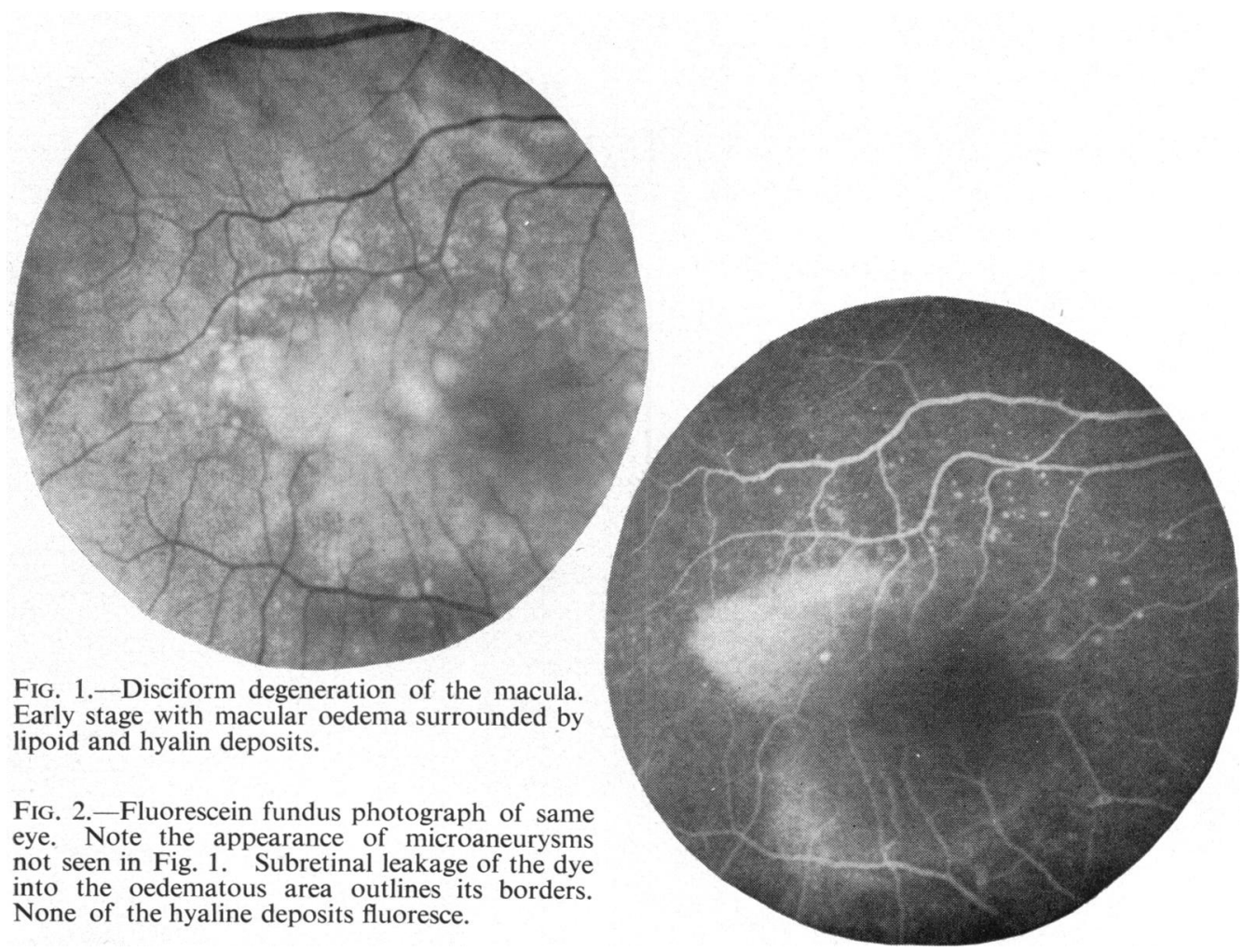

* Received for publication December 16, 1965.

† Address for reprints: as above. 


\section{Case Report}

A woman aged 60 years complained of defective vision in the right eye. In the right macula, temporally and overlapping the fovea, there was an irregular oedematous area, surrounded by yellow-white spots in the form of an incomplete ring (Fig. 1).

In the fundus of the left eye the typical disc-shaped pseudotumour was seen to project for several dioptres.

After intravenous injection of fluorescein (method of Novotny and Alvis, 1961) the dye appearing in the macular area filled not only the vessels but also some microaneurysms not visible by conventional ophthalmoscopy.

Simultaneously a diffuse glow rapidly extended into the oedema, becoming more and more distinct. None of the white spots fluoresced (Fig. 2).

20 seconds after injection many more microaneurysms were seen (Fig. 3). The glow of the central oedema was sharply outlined against the darker background, persisting unchanged for a longer period (Fig. 4).

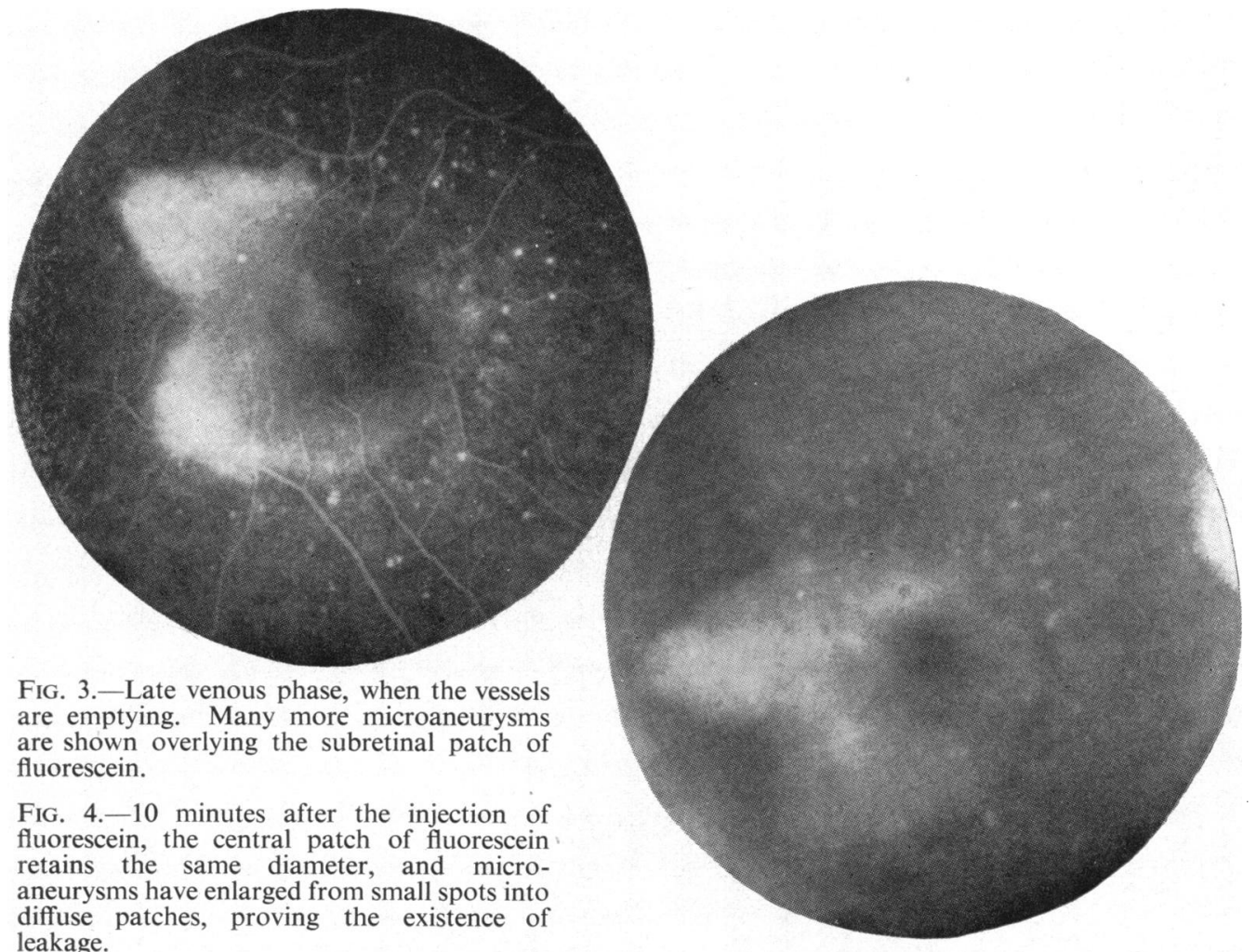

\section{Discussion}

Fluorescence angiography of disciform macular degeneration in an early stage shows two prominent features:

(1) Appearance of microaneurysms not to be seen by conventional ophthalmoscopy.

(2) Leakage of the dye in a circumscribed area coinciding with the visible macular oedema.

Microaneurysm, a specific retinal capillary lesion, is a common fundus change dominating the clinical picture of diabetic retinopathy and also appearing after the 
obstruction of retinal veins. It occurs in Coates's disease, in macroglobulinaemia, and other diseases of the retina. By introducing a contrast material into the fundus circulation, microaneurysms can be made to show up easily and in larger quantities than can be seen with the ophthalmoscope (Scott, Dollery, Hill, Hodge, and Fraser, 1963; Oosterhuis and Lammens, 1965).

Dollery and Hodge (1963) and Hodge and Dollery (1964) demonstrated microaneurysms in cases of hypertensive retinopathy which had been invisible before the technique of fluorescence ophthalmoscopy was developed.

The appearance of microaneurysms and also of hyaline and lipoid deposits are considered to be a response to chronic circulatory disturbances, the aneurysm formation being related to local hypoxia of the tissues (Ashton, 1963; Wise, 1961).

In disciform degeneration of the macula, hyaline and lipoid deposits are frequently scattered around the central lesion, and microaneurysms are revealed only by fluorescein. Assuming that the same trigger mechanism is responsible for the development of both, the findings of fluorescence angiography point to an underlying circulatory disturbance.

After the injection of fluorescein a choroidal mottling appears and at the same time a soft luminescence commences in the macular area. The wedge-shaped fluorescein patch rapidly extends to the central area of oedema outlining its borders. The patch continues to fluoresce for more than 10 minutes, retaining its diameter and clear outline. The similarity to the ophthalmoscopically visible oedema indicates that the oedematous fluid is staining, a phenomenon also observed by Hodge and Dollery (1964) in soft exudates.

The dye is assumed to leak from the vessels of the choroid. The small retinal vessels and some microaneurysms remain clearly visible, overlying the white patch of fluorescein, and moreover extravascular fluorescein from damaged retinal vessels shows a brighter luminescence and tends to blur and spread, whereas the soft glow of the central lesion retains its form unchanged. These findings suggest with reasonable assurance that the only possible points of leakage are in the choroid.

These changes permit the same conclusion as that reached by Hodge and Dollery (1964) in the interpretation of the staining of cotton-wool spots: fluorescein leaks into the wheal produced by the intradermal injection of histamine, and there is increased diffusion from damaged choroidal vessels and oedema fluid. The most interesting hypothesis regarding the pathogenesis of the disease is that offered by Sautter and Utermann (1964), who assumed the condition to be an arteriosclerotic chorioretinopathy of succulent type. The structural and nutritive characteristics of this area mean that retinal layers receive oxygen chiefly from the underlying choroid. According to Sautter and Utermann (1964), the condition arises from a series of events which corresponds to the arteriosclerotic process in the vascular wall, the first change in the fundus being a pathological transportation of substances from the choroid and the enhanced permeability of Bruch's membrane.

In disciform macular degeneration the first histological change is the appearance of transudate between the lamina elastica and the pigment epithelium, which soon spreads out between the outer retinal layers. Fluorescence ophthalmoscopy demonstrates histological findings in the living eye, supporting the view of Sautter and 
Utermann (1964). Besides providing evidence of the involvement of retinal capillaries in the form of microaneurysms, fluorescence studies demonstrate the source of the oedema in damaged choroidal vessels.

\section{Summary}

Vascular abnormalities in disciform degeneration of the macula-microaneurysms and subretinal leakage from choroidal vessels-are demonstrated by introducing fluorescein into the fundus circulation.

\section{REFERENCES}

Ashton, N. (1963). Brit. J. Ophthal., 47, 521.

Brown, E. V. L. (1940). Arch. Ophthal. (Chicago), 23, 1157.

Dollery, C. T., and HodGe, J. V. (1963). Trans. ophthal. Soc. U.K., 83, 115.

Hodge, J. V., and Dollery, C. T. (1964). Quart. J. Med., 33, 117.

Junius, P., and KuhNt, H. (1926). "Die scheibenförmige Entartung der Netzhautmitte". Karger, Berlin.

Novotny, H. R., and Alvis, D. L. (1961). Circulation, 24, 82.

Oosterhuis, J. A., and Lammens, A. J. J. (1965). Ophthalmologica (Basel), 149, 210.

Sautter, H., and Utermann, D. (1964). Klin. Mbl. Augenheilk., $145,1$.

Scott, D. J., Dollery, C. T., Hill, D. W., Hodge, J. V., and Fraser, R. (1963). Brit. J. Ophthal., 47, 588.

ThIEL, R. (1963). “Atlas der Augenkrankheiten", 6th ed., p. 533. Thieme, Stuttgart.

WiSE, G. N. (1961). Amer. J. Ophthal., 52, 637. 